\title{
American English influence on British English at the height of the British Empire: A case of cross-varietal easement
}

\author{
Donald S. MacQueen, Uppsala University
}

\section{$1 \quad$ Introduction}

The influence of the two major varieties of first-language English, American (AmE) and British (BrE), on each other has long been a vexed topic, but with the advent of computer-searchable and diachronic mega-corpora, the foundation for the discussion has become more and more scientific and thereby more nuanced. Albert Markwardt coined the term 'colonial lag' in $1958^{1}$ to capture a supposedly overriding pattern of language change between home-country and (formerly) colonial language varieties. This meant that changes in the English language normally started in the home country and were adopted only later, if ever, by speakers in the colonies or former colonies. The choice of term was unfortunate, as it not only ascribed a permanent central role to BrE and a peripheral one to AmE and other varieties but also implied a certain teleology: American English (AmE) lags behind British English (BrE) in its development and needs to catch up; the point of reference is the language of the home country that centuries ago launched colonies. We know, of course, that all language communities are in constant flux, so it stands to reason that varieties will always be changing in relation to each other, at different rates and along different parameters. With the advent of diachronic mega-corpus studies, it has become clear that Markwardt's 'lag' is merely one of many possible patterns of conservation and innovation between the varieties. ${ }^{2}$ The matter of language change and the influence of the respective main varieties on each other is becoming considerably more complex as we uncover diachronic patterns in the respective varieties.

This paper focuses on a grammatical pattern where there is virtually complete convergence between $\mathrm{AmE}$ and BrE today and where, for centuries, there also used to be virtually complete convergence between the two varieties but following an older pattern. The paper traces the historical shift from expressions involving the number word MILLION like: 
(1) It has about five millions of people...

Daily Telegraph editorial, May 27, 1910 (Corpus of English Newspaper Editorials, CENE)

(2) ...organizations representing five million people...

Michael W. Fox, Superpigs and Wondercorn: The Brave New World of Biotechnology and Where It All May Lead, 1992 (Frown Corpus)

Regarding the number word miLlion, example (1) differs from example (2) in two ways: s-inflection and the preposition of. These two features are associated with nouns in English, with s-inflection marking that the noun MILLION is plural in grammatical number and the preposition of typically separating two nouns in a partitive or genitive construction. While it is possible in modern terminology merely to analyze the phrase five millions of in (1) as a complex determiner of the noun phrase (NP) head people, this analysis sweeps under the carpet the sea change that English underwent regarding MILLION: the noun-related features of the phrase strongly suggest that in the older construction (1) MILLION was treated as a noun, the head of the NP, and post-complemented by the prepositional phrase of people. In contrast, the uninflected million without post-complementation in (2) functions as a (post-)determiner in an NP headed by people. In (2), MILLION is classified as a number word, like any other number word; in (1) MILLION is classified as a noun capable of heading a NP. The shift from noun to ordinary number word, or rather the integration of MILLION into the English system of number words, did not take place until several centuries after its introduction into English in the $14^{\text {th }}$ century, namely in the latter half of the $19^{\text {th }}$ century and the early $20^{\text {th }}$ century (for details, see MacQueen 2010). This paper will focus on the timing of the shift, with AmE preceding BrE by roughly a generation. The AmE example also seems to have hastened the change in $\mathrm{BrE}$, a case of what I have called cross-varietal easement, that is, the facilitation of a language change in one variety by usage in another variety (MacQueen 2010: 140, 165166).

\section{$2 \quad$ Method and material}

The sources searched for these AmE/BrE comparisons are extremely large, comprising tens of billions of words in total: Proquest's Historical Newspaper Collection (with complete runs of eleven major US newspapers, ${ }^{3}$ including advertising, from their start, usually in the $19^{\text {th }}$ century) and Gale Cengage's The Times Digital Archive (complete run of The Times of London from 1785 forward, including advertising). These sources involve methodological problems 
that stem from the fact that they cannot be run through a concordance program that would provide exact counts of instances of variants. ${ }^{4}$ Instead, users are limited to the companies' own software for searching the newspaper texts. This software returns a list of hits for each article or advertisement that contains at least one occurrence of the search string and also presents the hits highlighted in digital facsimiles of the newspaper pages. It is thus not possible to extract a running plain text version that could be concordanced. To overcome this limitation, I devised a measure of the 'proxy frequency' of variants, which counted the number of articles or the equivalent that included at least one instance of the search string. This means that the actual number might be much higher than the single proxy instance, but it was simply not feasible to manually scan the articles for further instances. Consistent use of the relative proxy frequency of the respective expressions per year yielded fully satisfactory readings for comparing the older and newer variants. Both sources were searched for two...ten millions vs. two...ten million for each year of publication, that is, nine searches for the millions variant and nine searches for the million variant for each year. ${ }^{5}$

\section{Results}

A series of corpora spanning different segments of the whole history of MILLION in English from the $14^{\text {th }}$ century onward had previously made it clear that the 'obsolescent' (Obs) form ${ }^{6}$ fully dominated usage for the first 500 years, up until the latter half of the $19^{\text {th }}$ century, when the present-day English (PdE) form began to gain acceptance. ${ }^{7}$ For an overview of the period surrounding this change, Historical Newspapers Collection and The Times Digital Archive were first searched for two millions vs. two million only. Figures 1 and 2 present aggregated figures per decade for the respective collections. The two lines in each figure are mirror images of one another, of course, representing the Obs and PdE constructions respectively. 


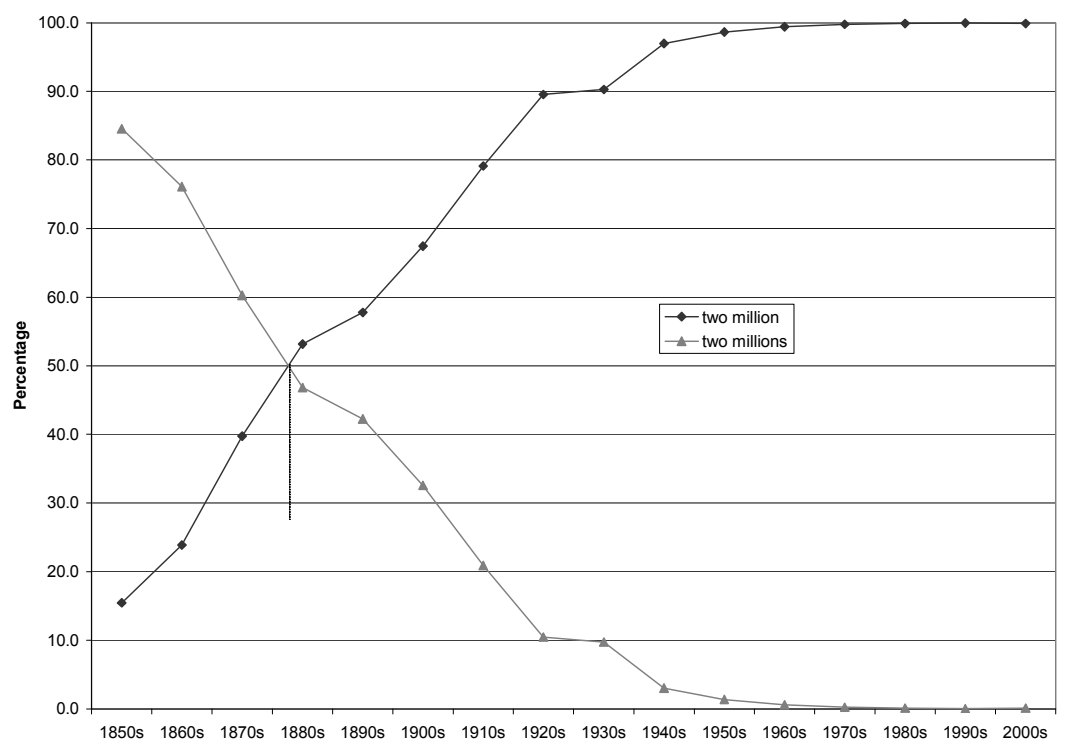

Figure 1: Percentage of two million vs. two millions in Historical Newspapers Collection, per decade, 1850-2000, based on number of articles containing at least one instance of the respective construction 


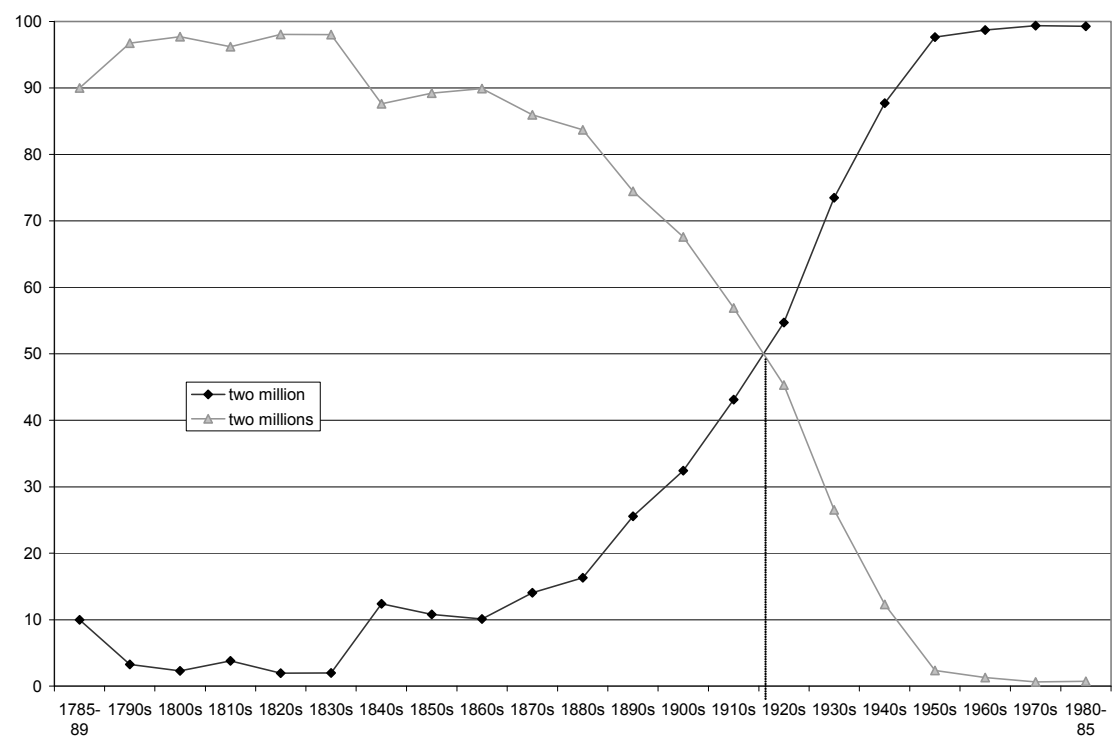

Figure 2: Percentage of two million vs. two millions in The Times Digital Archive, per decade, 1785-1985, based on number of articles containing at least one instance of the respective construction

Figures 1 and 2 show that the intersections of the two lines, that is, the points where the Obs and $\mathrm{PdE}$ constructions were equally frequent in $\mathrm{AmE}$ and $\mathrm{BrE}$ respectively, occur in the early 1880 s and early 1920 s respectively. This rough point of parity can be examined in more detail by looking at annual data for each of the two newspaper collections over a sixty-year period, that is, about thirty years either side of the respective apparent points of parity, as seen in Figures 3 and 4: 


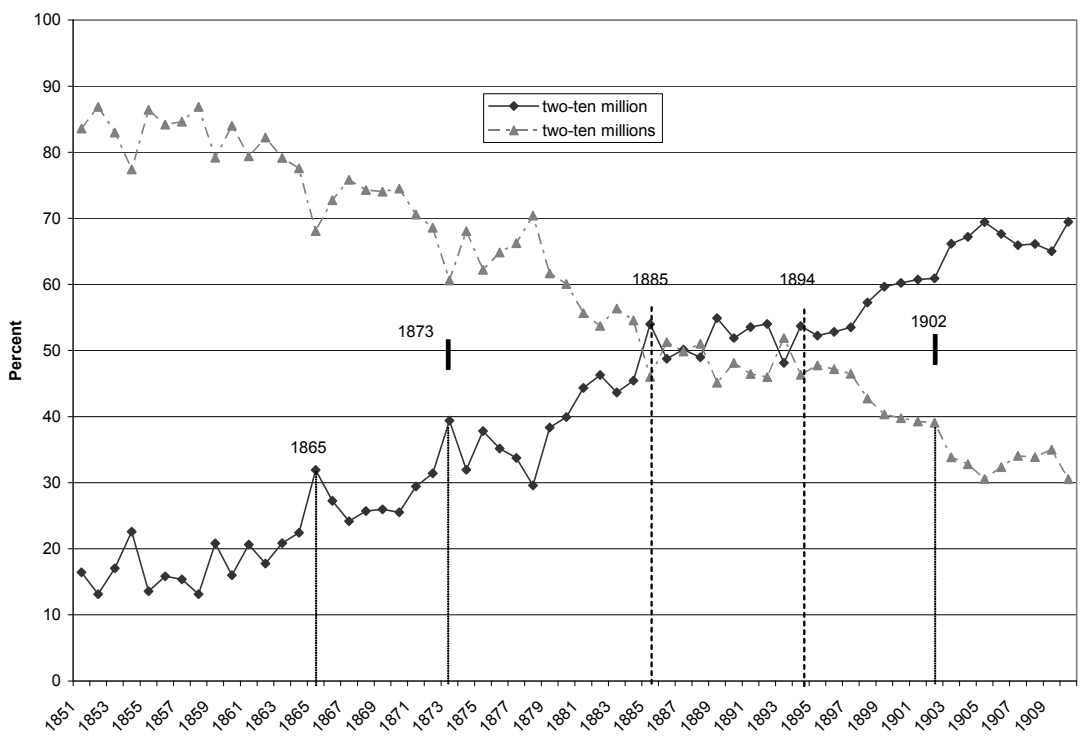

Figure 3: Percentage of two...ten million vs. two...ten millions in Historical Newspapers Collection per year, 1851-1910, based on the number of articles containing at least one instance of the respective constructions 


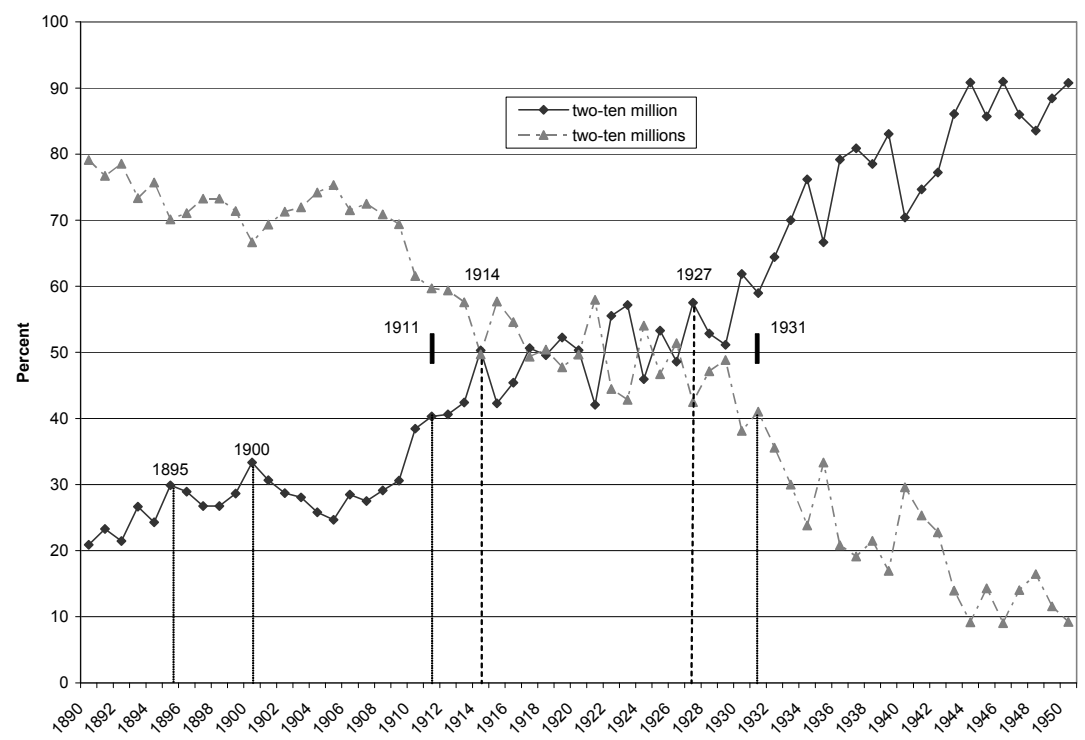

Figure 4: Percentage of two...ten million vs. two...ten millions in The Times Digital Archive per year, 1890-1950, based on the number of articles containing at least one instance of the respective constructions

Again, the lines in both figures mirror each other. Dates have been provided to highlight five arbitrary milestones when the new usage rose to 30, 40, and 50 percent, respectively, and further when its predominance became permanent and when the share reached 60 percent. Thus, in Figure 3, the point of parity in the early 1880 s presented in Figure 1 is flanked by annual turmoil from 1873 through 1902, as marked by the two bold vertical lines in the figure, if the corridor for 'turmoil' is set at approximately 10 percentage points either side of 50percent parity. This is a 29 -year period. Some of the turbulence can no doubt be ascribed to sampling problems, but the large number of instances from each year makes this pattern credible as a sketch of actual usage in U.S. quality newspapers across the period. The slope from about 20 percent in 1851 to about 70 percent in 1910 is remarkably steady and straight over the 60-year period.

Figure 4 shows the same parameters as Figure 3, but this time for Times Digital Archive. The time span covered by the two figures is the same $(\sim 60$ years), and in each figure the line tracing the adoption of the PdE expression 
starts from roughly the same percentage level ( 20 percent). But over the 60 year period the line representing usage in The Times reaches the level of 90 percent of usage, while the corresponding line for Historical Newspapers rises only to 70 percent. In other words, the slope of the line in Figure 4 is steeper than that of the line in Figure 3, meaning that the shift from the previously dominant Obs expression to the PdE expression was more rapid in the case of the British newspaper. Further, the vertical lines marking the years when the proportions were 40-60 percent and 60-40 percent, respectively - in Figure 4 the years 1911 and 1931 - are separated by 20 years. The corresponding period in Figure 3 - from 1873 to 1902 - spans $\sim 30$ years, roughly 50 percent longer.

\section{Discussion and conclusions}

It may be that the difference in the rate of the shift is partly due to the circumstance that the British sample is from a single newspaper and the American sample from several, although if this were simply a matter of a house style, the shift would clearly have been much more abrupt. The most likely reason for the more rapid, but nevertheless gradual, adoption of the PdE expression in The Times is the fact that American usage was already in the realm of 60-70-percent dominance for the PdE expression when the shift got underway in the UK. While it is difficult to determine precisely what prompted BrE usage to change, it is tempting to suggest that changing AmE usage had some sway, perhaps triggering the beginning of a shift in BrE and even more likely causing the change, once started, to be faster in the UK than it had been in the US, where there was no model in which the PdE expression was dominant.

The shift in usage in the two varieties took place during the period that witnessed both the peak of the British Empire and the eclipsing of Britain by the US as the world's largest economy. This influence of AmE on BrE usage - here limited to newspaper usage, but probably applicable to usage in general - is likely a case of what could be called cross-varietal easement. While they were difficult to discern in the past, numerous examples of such directional influence will no doubt be uncovered regarding several parameters as reliable diachronic megacorpora continue to be mined for patterns in usage across varieties and time.

\section{Notes}

1. American English, pp. 59-80, New York: Oxford University Press.

2. See especially Marianne Hundt, Colonial lag, colonial innovation, or simply language change? in Günter Rohdenburg and Julia Schlüter (eds.), One 
language, two grammars? (2009). The other contributions present numerous reconsiderations of conventional thinking about grammatical differences and influences between $\mathrm{AmE}$ and BrE.

3. The collection has since added more newspapers, including some from outside the US. The software allows users to select among these newspapers in their searches.

4. For this to be possible, users would have to be able to download the entire texts for analysis, which would violate the proprietary rights of Proquest and Gale Cengage.

5. For Historical Newspapers Collection the search was not simple but rather involved the use of wildcard characters to distinguish between the inflected and uninflected forms. For details, see MacQueen (2010), Chapter 5.

6. I refer to the older form (e.g. five millions of) as 'obsolescent' rather than 'obsolete' as it is still in common use in India and Kenya, among other countries. It still occurs in $\mathrm{AmE}$ and $\mathrm{BrE}$ as well, though only very rarely now.

7. For suggested accelerating and retarding factors, see MacQueen (2010), Chapters 6 and 7 respectively.

\section{References}

Hundt, Marianne. 2009. Colonial lag, colonial innovation, or simply language change? In G. Rohdenburg and J. Schlüter (eds.). One language, two grammars?, 13-37. Cambridge: Cambridge University Press.

MacQueen, Donald. 2010. The integration of MILLION into the English system of number words: A diachronic study. Frankfurt: Peter Lang.

Markwardt, Albert. 1958. American English. New York: Oxford University Press.

Rohdenburg, Günter and Julia Schlüter (eds.). 2009. One language, two grammars? Cambridge: Cambridge University Press. 